\title{
RICKETS FOLLOWING AN ATTACK OF ACUTE NEPHRITIS
}

\author{
BY \\ E. A. COCKAYNE, M.D., F.R.C.P., \\ and \\ F. P. LEE LANDER, M.R.C.P. \\ (From the Middlesex Hospital, London.)
}

Renal rickets, although a rare disease, has received an amount of attention in the literature out of proportion to its importance or the frequency of its occurrence. This undue prominence is probably on account of its bearing on infantile rickets, and also on the difficult problem of calcium and phosphorus metabolism.

It is not intended to give here a complete review of the literature, but to mention only those papers which deal with the clinical aspect of the disease, and then to discuss briefly some bio-chemical findings in the condition, and some hypotheses of the pathogenesis of the rickets.

Barber $^{1}$ in a series of papers gives the records of some 17 cases, which have been either under his care, or to which he has had direct clinical access. This is the largest series reported by one author. All Barber's patients were children under the age of 12 , and in no case was a definite history of acute nephritis obtained. The children are presented on account of stunted growth, knock-knee, or excessive thirst with frequency of micturition.

Clinical examination provides remarkably little information. The cardiovascular system is usually normal; there being no cardiac enlargement, a normal blood-pressure, usually no retinal changes, and no palpable thickening of the arteries. The skeleton may show deformities, either dwarfism or genu valgum being present. The urine is pale in colour, of low specific gravity, and usually shows a trace of albumin, though it may be albumin-free for many days at a time. The disease is chronic in its course, but ultimately the patient succumbs to renal insufficiency. Pathologically, the kidneys show changes which approximate to those found in senile arterio-sclerotic kidneys. In most cases the heart is of normal weight and the peripheral arteries are unchanged.

Parsons $^{2}$ discusses the disease mainly from the radiological and biochemical points of view, and comes to the conclusion that renal rickets is a low-calcium type of rickets. In order to explain the normal serum calcium which is frequently found in the condition, he postulates an over-action of 
the parathyroids in the attempt on the part of the body to prevent the occurrence of tetany. Mitchell ${ }^{3}$, in an exhaustive article, presents 200 cases of chronic renal disease in children collected from the literature. In only 76 of these was he able to find references to skeletal deformities, the majority of these 76 cases showing genu valgum. In only 2 of the cases collected by Mitchell was the renal lesion definitely secondary to acute nephritis. Both of these were reported by Brockman ${ }^{4}$.

\section{Case report.}

The case reported below has several unusual features. The nephritis was secondary to an attack of acute nephritis, and the patient was under observation the whole time for nephritis. The rapidity of the advancement of the lesion and the early death of the patient, also constitute features absent from the common form of the disease.

R. W., male, aged 13 years, gave a history of chicken-pox and whooping-cough in infancy. He had attended hospital, at 7 years, on account of his mental condition, and a diagnosis of amentia was made. Unfortunately there is no record of an examination of the urine. Wassermann reaction was negative.

In March, 1928, the patient, then 10 years old, was admitted to the Hospital for Sick Children, Great Ormond Street, suffering from odema of the face and legs, and marked hæmaturia.

On examination the patient was found to be a well-developed boy of a sullen backward disposition. OEdema of the face was so great that he was unable to open his eyes. The chest, abdominal wall, and legs were very oedematous. Ascites was present, and also small bilateral pleural effusions. The heart's apex-beat was $\frac{1}{2}$-in. outside the nipple line. Blood pressure $=150 / 90$. The urine showed a sp. gr. 1025, with albumin $1.2 \mathrm{grm}$. per litre. The blood urea $=54 \mathrm{mgrm}$. per $100 \mathrm{c.cm}$., and the blood cholesterol $=325$ mgrm. per litre. His weight was $87 \mathrm{lb}$.

From admission the condition of the patient gradually improved. The odema disappeared within six weeks, the blood pressure fell to $100 / 70$, but the nitrogen retention persisted throughout the patient's stay in hospital. The daily output of urine varied between 10 and $45 \mathrm{oz}$., with a daily average of $26 \mathrm{oz}$.

In June, 1928, the ascites and pleural effusions were still present. An examination of the blood gave the following values:-urea, $59 \mathrm{mgrm}$. per $100 \mathrm{c.cm}$.; cholesterol, $338 \mathrm{mgrm}$. per $100 \mathrm{c.cm}$; serum calcium, 7.7 mgrm. per $100 \mathrm{c.cm}$. The patient was discharged at the end of July, 1928, to a convalescent home.

He next attended the hospital in January, 1929, as an out-patient. He was found to have odema of the face and legs. The urine was of sp. gr. 1002, with a heavy cloud of albumin, but no blood. Weight, $79 \mathrm{lb}$. The boy attended regularly at monthly intervals until January, 1930. After the first examination, the urine never contained more than a trace of albumin, and the cedema was confined to the lower part of the legs.

From January, 1930, the patient attended as an out-patient at the Middlesex Hospital, and was seen every month until September, 1931. During this period the amount of albumin in the urine gradually increased, but the odema remained unobtrusive. In September it was noticed that the patient had developed genu valgum, which, his mother said, had been present for about six weeks. The patient 
was recommended for admission, and came into hospital early in October, when his condition was found to be as follows:-The heart's apex-beat was outside the nipple line in the fifth space. The aortic second sound was accentuated. Blood pressure $=140 / 105$. There was no œdema and no ascites.

There was marked genu valgum. No other clinical evidence of skeletal deformity could be found.

The retinæ showed blurring of the optic discs with exudates, but no hæmorrhages.

The patient felt quite well, and did not suffer from headaches and did not vomit.

Blood analysis on admission:-urea, 100 mgrm. per 100 c.cm.; non-protein nitrogen, 66 mgrm.; serum calcium, 7.5 mgrm.; phosphates, 9.8 mgrm.

The urine was of sp. gr. 1010. Albumin=4 grm. per litre.

$\mathrm{X}$-ray examination showed typical rickety changes at the knee- and wrist-joints.

After seventeen days stay in hospital, the patient's condition became suddenly worse. He developed intractable vomiting and a very severe headache. Two days later he became comatose, with fine muscular twitchings, and died.

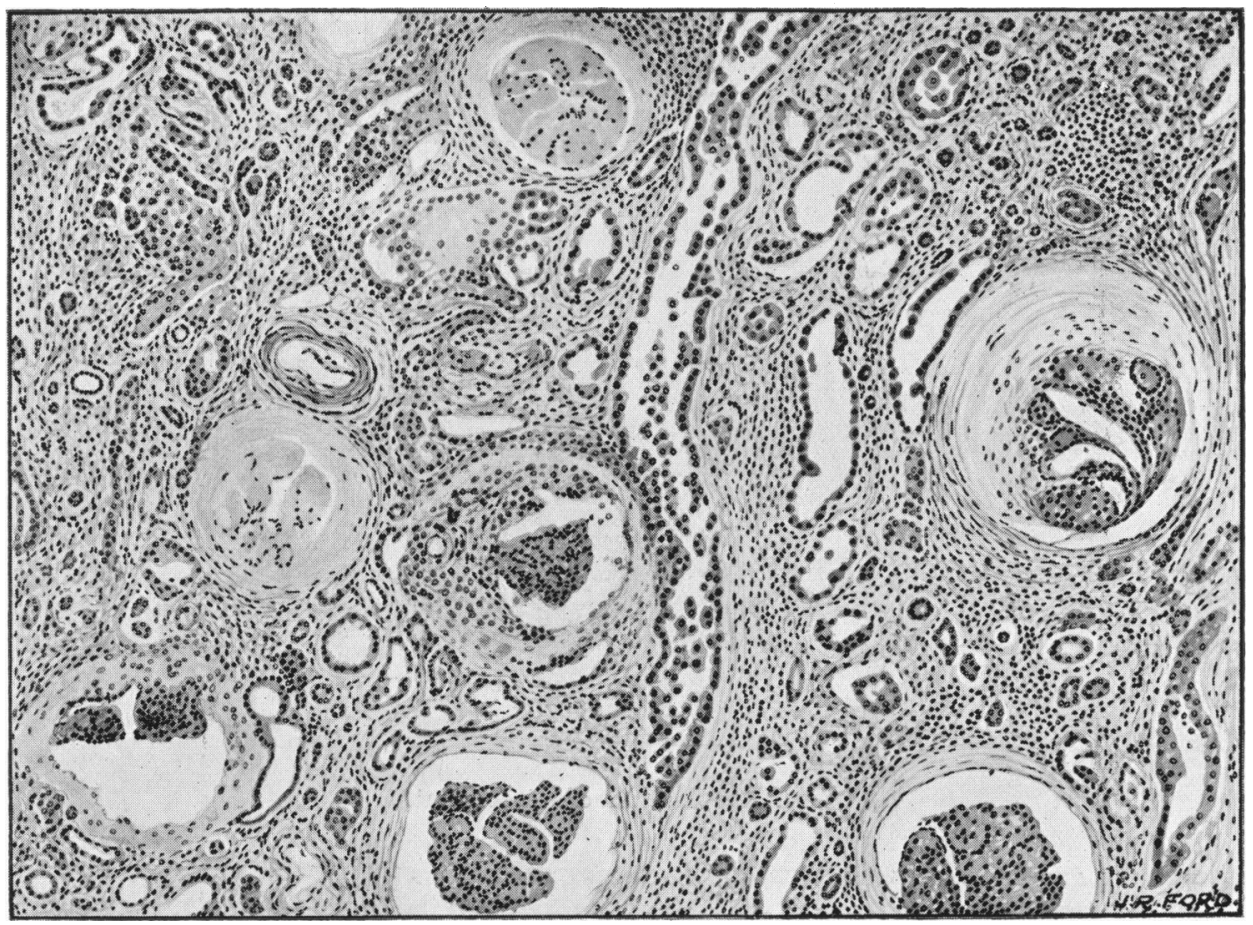

FIG. 1.-Section of kidney ( $\times$ 125).

Post-mortem examination.-KIDNEYs. Macroscopically, both kidneys were smaller than normal and pale in colour, the capsules stripped with difficulty leaving a granular surface. On section the cortices were narrowed with complete loss of the cortical pattern.

Microscopically, the kidney showed considerable disorganization, most of the glomeruli being affected. Large numbers of glomeruli were completely fibrosed, and or the remainder many showed proliferative glomerulitis and capsulitis of varying degree: a few showed ischæmic changes. The secreting tubules were dilated, with degeneration and thinning of the epithelium; many contained hyaline and finely 
granular casts. The interstitial tissue was greatly increased in amount and contained numerous foci of chronic inflammatory cells.

Bones. The gross deformities have already been described. Section of the bones showed them to be softer than normal with broad and irregular epiphyseal lines.

Microscopically, the general appearances were those of true rickets. The epiphyseal cartilages were thickened with increase of the zone of proliferating cartilage; the vascular invasion of this zone was irregular leaving islets of unchanged cartilage on the metaphyseal side. An excessive amount of osteoid tissue was

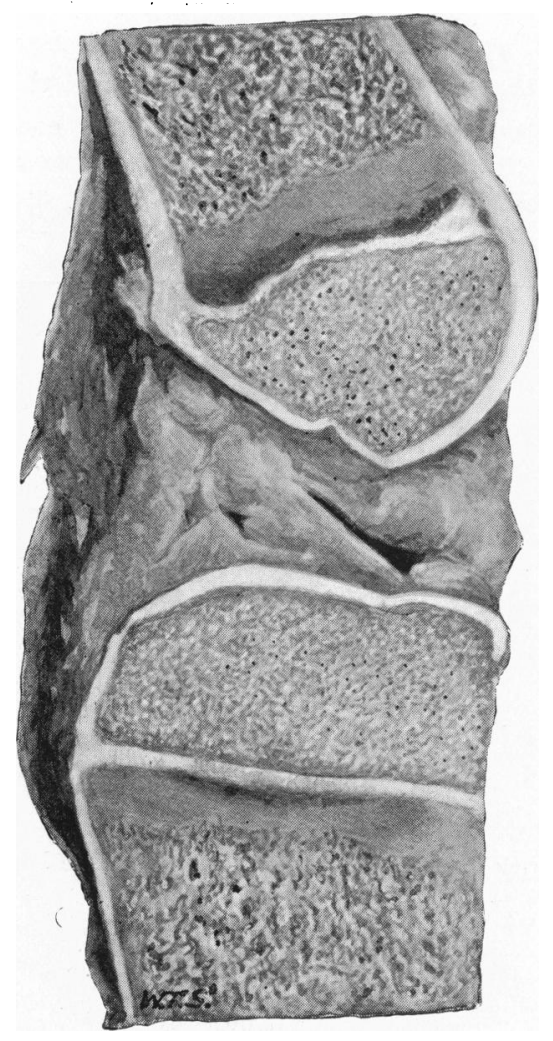

Fig. 2.-Section of knee-joint.

present and there was no hæmatogenous marrow for a considerable distance up the shafts, the marrow spaces being occupied by fine fibrillar connective tissue.

OTHER Organs. Except for some hypertrophy of the left ventricle nothing relevant was found.

Summary. The post-mortem findings are therefore those of chronic glomerulotubular nephritis with left ventricular hypertrophy, accompanied by bony changes resembling those of true rickets.

\section{Discussion.}

The outstanding feature of the case is the rapidity with which the disease passed through all its phases to a fatal issue. The patient developed acute 
nephritis in March, 1928; in April and the following months, the subacute phrase of the disease had set in; genu valgum appeared in September, 1931, when the disease had reached the chronic phase; and death occurred in November, 1931, about $3 \frac{1}{2}$ years after the initial attack.

From a study of this case, it is seen that bony changes occur in chronic renal disease of inflammatory origin, as well as in renal disease of doubtful, and probably degenerative, origin of childhood. The bony changes are the result of the disturbances in calcium and phosphorus metabolism. Hess" states that the earliest change in true rickets is a rise in the phosphate level in the blood, and in this case the blood phosphate value (in one isolated finding) was markedly above normal, three years before bone changes became manifest.

Mitchell ${ }^{3}$ advances the hypothesis that the bony changes are due to a calcium deprivation, which is secondary to retention of phosphates by the kidneys. He states that there is a greatly increased excretion of phosphates by the bowel, and this interferes with calcium absorption by forming insoluble calcium phosphates, which are excreted, as such, in the fæces. In the light of our present knowledge this is unlikely, as calcium and phosphorus are thought to be absorbed in the small intestine and are both excreted at a lower level. Thus at the site of calcium absorption, the phosphorus concentration in the bowel should be normal.

Various authors have objected to the identification of the skeletal changes in renal rickets with those of true rickets, not so much because the pathological picture varies from that found in true rickets, but because the phosphate-calcium ratio is usually above 40 , and in true rickets it is always found to be below this figure. This reasoning is unsound, because it is attempting to fit the facts of the problem to a particular hypothesis, and not, as it should be, formulating an hypothesis to fit the known facts.

In an unpublished case, one of us (E.A.C.) has noted a greatly increased phosphatase in the blood, and this would correspond with the raised level found in true rickets. The significance of the blood phosphatase is as yet imperfectly understood, so it would be meaningless to attempt to build arguments on this finding.

Treatment is directed solely against the nephritis, and as would be expected, no drug or diet influences the course of the disease. The inevitable end may be hastened by operative interference to the genu valgum, and this has happened in a number of instances, in which, at the time of examination, albuminuria was absent.

We wish to acknowledge our indebtedness to Dr. Robert Hutchison for allowing us the use of his ward notes. Also we wish to thank the director of the Bland-Sutton Institute of Pathology for putting at our disposal the pathological data; and the professor of the Courtauld Institute of Biochemistry, and Dr. Payne, for the figures relating to the blood chemistry. 
REFERENGES.

1. Barber, H., Quart. J. Med., Oxford, 1921, XIV, 205; Guys Hospital Rep., Lond., 1926, LXXVI, 307.

2. Parsons, L. G., Arch. Dis. Childh., Lond., 1927, II, 1 \& 198.

3. Mitchell, A. G., Am. J. Dis. Child., Chicago, 1930, XL, 101 \& 345.

4. Brockman, E. P., Brit. J. Surgery, Bristol, 1926-7, XIV, 634.

5. Hess, A. F., Rickets, Osteo malacia and Tetany, N.Y., 1930. 